\title{
Functional test of pedotransfer functions to predict water flow and solute transport with the dual-permeability model MACRO
}

\author{
J. Moeys ${ }^{1}$, M. Larsbo ${ }^{1}$, L. Bergström ${ }^{1}$, C. D. Brown ${ }^{2}$, Y. Coquet $^{3}$, and N. J. Jarvis ${ }^{1}$ \\ ${ }^{1}$ Department of Soil and Environment, SLU, P.O. Box 7014, 75007 Uppsala, Sweden \\ ${ }^{2}$ Environment Department, University of York, Heslington, York, YO10 5DD, UK \\ ${ }^{3}$ AgroParisTech, UMR1091 Environment and Arable Crops, BP01, 78850 Thiverval-Grignon, France
}

Correspondence to: J. Moeys (julien.moeys@ slu.se)

Received: 25 January 2012 - Published in Hydrol. Earth Syst. Sci. Discuss.: 20 February 2012

Revised: 30 May 2012 - Accepted: 6 June 2012 - Published: 12 July 2012

\begin{abstract}
Estimating pesticide leaching risks at the regional scale requires the ability to completely parameterise a pesticide fate model using only survey data, such as soil and land-use maps. Such parameterisations usually rely on a set of lookup tables and (pedo)transfer functions, relating elementary soil and site properties to model parameters. The aim of this paper is to describe and test a complete set of parameter estimation algorithms developed for the pesticide fate model MACRO, which accounts for preferential flow in soil macropores. We used tracer monitoring data from 16 lysimeter studies, carried out in three European countries, to evaluate the ability of MACRO and this "blind parameterisation" scheme to reproduce measured solute leaching at the base of each lysimeter. We focused on the prediction of early tracer breakthrough due to preferential flow, because this is critical for pesticide leaching. We then calibrated a selected number of parameters in order to assess to what extent the prediction of water and solute leaching could be improved.

Our results show that water flow was generally reasonably well predicted (median model efficiency, ME, of 0.42). Although the general pattern of solute leaching was reproduced well by the model, the overall model efficiency was low (median $\mathrm{ME}=-0.26$ ) due to errors in the timing and magnitude of some peaks. Preferential solute leaching at early pore volumes was also systematically underestimated. Nonetheless, the ranking of soils according to solute loads at early pore volumes was reasonably well estimated (concordance correlation coefficient, CCC, between 0.54 and 0.72). Moreover, we also found that ignoring macropore flow leads to a significant deterioration in the ability of the model to reproduce the observed leaching pattern, and especially the early
\end{abstract}

breakthrough in some soils. Finally, the calibration procedure showed that improving the estimation of solute transport parameters is probably more important than the estimation of water flow parameters. Overall, the results are encouraging for the use of this modelling set-up to estimate pesticide leaching risks at the regional-scale, especially where the objective is to identify vulnerable soils and "source" areas of contamination.

\section{Introduction}

Pesticide fate modelling for estimation of leaching risks over large areas is a challenge. It requires taking into account complex non-linear processes such as water movement, pesticide sorption and degradation in soils, and it requires estimating numerous model parameters. Indeed, it is technically impossible to measure these parameters over large areas, so most - if not all - of them must be estimated from agroenvironmental information about soils, landscape features, pesticide properties, crop rotations and climate that are easier to obtain from survey data such as soil maps. Both class and continuous statistical models can be used to relate elementary agro-environmental conditions to model parameters (Wösten et al., 1999; Schaap et al., 2001). These estimation procedures - referred to here as "parameter estimation algorithms" - are generally called "pedotransfer functions" (PTFs) when they concern soil properties. The survey data used to obtain agro-environmental conditions are derived from measured point data, or remotely sensed spatial data, and are therefore only estimations of their "true" spatio-temporal variations.

Published by Copernicus Publications on behalf of the European Geosciences Union. 
So estimating pesticide leaching risks over large areas necessarily relies on a complete parameter inference system (Wagenet and Hutson, 1996; Soutter and Pannatier, 1996; Tiktak et al., 2002; Leterme et al., 2007), linking data and information on scarce measurements of agro-environmental conditions to fully parameterize a pesticide fate model. In such complex inference systems, sources of error are numerous (Dubus et al., 2003; Deng et al., 2009; Boesten, 2000; Heuvelink et al., 2010; Leterme et al., 2007): (1) errors or uncertainties in the estimations of the agro-environmental geographic information system; (2) errors in the parameter estimation algorithms; (3) failure of the model to accurately reproduce the processes, also called structural errors; and (4) errors arising from choices made by the modeller. Despite these possible sources of uncertainty, inference systems for estimating pesticide leaching risks are expected to become increasingly important tools for supporting work aimed at reducing the diffuse pollution of water bodies by pesticides. Indeed, the European "Thematic Strategy on the Sustainable use of Pesticides" (Commission of The European Communities (CEC), 2006) is expected to reinforce the need for tools allowing users to estimate where in the landscape a given pesticide, or pesticide program, may pose a risk. It is thus essential to have a clearer idea of the reliability of these inference systems.

Inference systems can be evaluated in different ways. Their ability to predict model parameter values can be directly tested against databases of measured data (Vereecken et al., 2010). However, the number of parameters that needs to be tested is large, and there can be important scale differences between the processes described in the model and the samples used to test the inference system. Alternatively, the inference system can be tested together with the model for its ability to reproduce measurements of water and solute transport in soils. This "functional" approach (Finke et al., 1996) also implicitly accounts for parameter sensitivity: errors in the estimation of the most sensitive parameters will affect the predictions more than errors in the estimation of less sensitive parameters.

Including a given process into pesticide risk assessments not only requires being able to model the process at stake, but also being able to estimate the parameters of the model related to this process with sufficient precision. For example, processes such as kinetic sorption are generally not considered, because little is known about how the parameters can be estimated from survey data. Until recently, this was also the case for preferential flow in soils. Despite an increasing amount of experimental evidence proving that preferential flow occurs quite frequently (Jarvis, 2007), and despite a large body of literature on preferential flow modelling (Gerke, 2006; Šimùnek et al., 2003), the process has not been considered in regional modelling of pesticide leaching risks. The recently completed FOOTPRINT EU-FP6 project made significant progress regarding our understanding of the agropedological factors triggering preferential flow in soil (Jarvis,
2007), methodologies for predicting the extent of macropore flow (Jarvis et al., 2009; Lindahl et al., 2009) and the estimation of macropore flow parameters in the dual-permeability model MACRO (Jarvis et al., 2007).

This paper presents the parameter estimation algorithms in the FOOTPRINT inference system, including those for macropore flow, and evaluates the ability of MACRO to predict solute leaching breakthrough when parameterised in this way. Our aim was to assess the ability of the MACRO model to predict solute leaching in soils when only basic site, soil and crop properties are available and model parameters are estimated from estimation algorithms (i.e. no calibration is done). Although the ultimate goal is to predict regional-scale leaching of pesticides, we focused in this study on tracer transport, since one key question is the reliability of the pedotransfer functions used to estimate transport parameters in MACRO, especially those related to macropore flow. Predictions of pesticide leaching are also very sensitive to uncertainty in sorption and degradation parameters (Vanderborght et al., 2011), which might overshadow the effects of errors in transport parameterisation. Estimating the impact of uncertainties in sorption and degradation on pesticide leaching is therefore out of the scope of this work. We compared MACRO simulations of water flow and tracer leaching from 16 different soils against measurements from cropped lysimeters containing undisturbed soils exposed to natural long-term weather conditions. In a second step, we used a simple procedure to investigate the potential for improving the simulation results by calibrating two parameters important for water flow simulations and two parameters important for solute transport. We also quantified the deterioration in model predictions that occur when macropore flow is neglected.

\section{Materials and methods}

\subsection{Lysimeter studies and weather data}

We collected 16 datasets describing lysimeter experiments carried out in six different studies in Sweden, France and the United Kingdom. Table 1 summarises the major characteristics of the 16 lysimeter experiments, and Table 2 summarises the properties of the different soils.

The first study ("Ultuna 1") includes five soil types from southern and central Sweden included in a long-term soil fertility experiment (Ekebo, Fjärdingslöv, Högåsa, Kungsängen and Vreta soils). Detailed soil descriptions can be found in Kirchmann et al. (1999, 2005) and Kirchmann (1991). Replicate one-meter-long lysimeters were collected in 1999 (Djodjic et al., 2004). Bromide leaching experiments were conducted in these soils between mid-October 2007 and December 2008 , at Ultuna, Uppsala $\left(59.82^{\circ} \mathrm{N}, 17.65^{\circ} \mathrm{E}\right)$. The weather station was located less than a kilometre away from 
Table 1. Characteristics of the lysimeter experiments used for assessing MACRO and FOOTPRINT estimation algorithms.

\begin{tabular}{|c|c|c|c|c|}
\hline Experiment location & Experiment reference & $\begin{array}{r}\text { Time frame } \\
\text { [year] }\end{array}$ & $\begin{array}{r}\text { Duration } \\
\text { [days] }\end{array}$ & Soils (number of replica) \\
\hline Ultuna 1 (Sweden) & $\begin{array}{l}\text { Larsbo M., unpublished data } \\
\text { Soils from Dojdjic et al. (2004) }\end{array}$ & 2007-2008 & $311-434$ & $\begin{array}{l}\text { Ekebo (5), Fjärdingslöv (5), Högåsa (5), } \\
\text { Kungsängen (5), Vreta (4) }\end{array}$ \\
\hline Ultuna 2 (Sweden) & Bergström and Jarvis (1993) & 1989-1990 & 307 & Mellby (2) \\
\hline Ultuna 3 (Sweden) & Bergström et al. (2011) & 2006-2008 & 711 & Lanna (4), Nåntuna (4) \\
\hline Villamblain (France) & Vachier P., unpublished data & 1995-1998 & 975 & Villamblain ( 2 soils, 1 rep. each) \\
\hline Silsoe (UK) & Brown et al. (2000) & 1994-1996 & 529 & $\begin{array}{l}\text { Cuckney (2), Sonning (1), Ludford (2), } \\
\text { Enborne (2), Isleham (2) }\end{array}$ \\
\hline Brimstone (UK) & Beulke et al. (2001) & 1994-1995 & 38 & Brimstone (2) \\
\hline
\end{tabular}

Table 2. Characteristics of the different soils. Texture classes are given according to the USDA system ("Cl" = "Clay", "Si" = "Silt" or "Silty", "Sa" = "Sand" or "Sandy" and "Lo" = "Loam" or "Loamy"). Texture, organic carbon, bulk density and stone content values are the average values of the different layers concerned weighted by their thicknesses.

\begin{tabular}{|c|c|c|c|c|c|c|c|c|}
\hline Name & Soil type & $\begin{array}{l}\text { Topsoil } \\
\text { texture }\end{array}$ & $\begin{array}{l}\text { Subsoil } \\
\text { texture }\end{array}$ & $\begin{array}{r}\text { Topsoil } \\
\text { OC }\end{array}$ & $\begin{array}{r}\text { Bulk } \\
\text { density }\end{array}$ & $\begin{array}{r}\text { Stone } \\
\text { content }\end{array}$ & $\begin{array}{r}\text { Profile } \\
\text { depth }\end{array}$ & $\begin{array}{r}\text { Number of } \\
\text { horizons } \\
\text { in profile }\end{array}$ \\
\hline & & & & $(\%)$ & $\left(\mathrm{kg} \mathrm{dm}^{-3}\right)$ & $(\%)$ & (m) & $(-)$ \\
\hline Ekebo & Oxyaquic Eutrocept ${ }^{1}$ & Lo & Lo & 2.4 & 1.45 & 6 & 1.0 & 6 \\
\hline Fjärdingslöv & Oxyaquic $^{1}$ & SaLo & SaLo & 1.3 & 1.69 & 3 & 1.0 & 5 \\
\hline Högåsa & Humic Dystrocryept $^{1}$ & LoSa & $\mathrm{Sa}$ & 1.7 & 1.42 & 0 & 1.0 & 6 \\
\hline Kungsängen & Typic Haplaquept $^{1}$ & $\mathrm{Cl}$ & $\mathrm{Cl}$ & 2.1 & 1.31 & 0 & 1.0 & 3 \\
\hline Vreta & Oxyaquic Haplocryoll $^{1}$ & $\mathrm{Cl}$ & $\mathrm{Cl}$ & 1.7 & 1.43 & 0 & 1.0 & 5 \\
\hline Mellby & Uderic Haploboroll $^{1}$ & SaLo & $\mathrm{Sa}$ & 3.4 & 1.33 & 0 & 1.0 & 4 \\
\hline Lanna & Fluventic Haplumbrept ${ }^{1}$ & $\mathrm{SiCl}$ & $\mathrm{Cl}$ & 2.4 & 1.35 & 0 & 1.1 & 4 \\
\hline Nåntuna & (unknown) & LoSa & $\mathrm{Sa}$ & 1.2 & 1.43 & 0 & 1.1 & 5 \\
\hline Villamblain 1 & Eutric Cambisol/Haplic Calcisols 2,3 & SiClLo & Lo & 1.4 & 1.16 & 25 & 1.5 & 4 \\
\hline Villamblain 2 & Eutric Cambisol/Haplic Calcisols ${ }^{2,3}$ & SiClLo & Lo & 1.4 & 1.16 & 18 & 1.5 & 5 \\
\hline Cuckney & Argic ustipsamment ${ }^{1}$ & $\mathrm{Sa}$ & $\mathrm{Sa}$ & 0.7 & 1.51 & 1 & 1.1 & 4 \\
\hline Sonning & Udic paleudalf $^{1}$ & SaLo & SaLo & 1.0 & 1.57 & 33 & 1.1 & 5 \\
\hline Ludford & Ultic haplustalf $^{1}$ & SaLo & SaLo & 1.0 & 1.79 & 0 & 1.1 & 5 \\
\hline Enborne & Vertic fluvaquent ${ }^{1}$ & SaClLo & SaClLo & 4.0 & 1.12 & 8 & 1.1 & 5 \\
\hline Isleham & Terric medisaprist $^{1}$ & Lo & SaLo & 28.9 & 0.69 & 0 & 1.1 & 6 \\
\hline Brimstone & pelo-stagnogley Denchworth series ${ }^{4}$ & $\mathrm{Cl}$ & - & 3.3 & 1.15 & 0 & 0.3 & 2 \\
\hline
\end{tabular}

${ }^{1}$ USDA Soil Survey classification; ${ }^{2}$ World Reference base for Soil Classification; ${ }^{3}$ Soils in Villamblain present heterogeneities between and within the soil profiles; ${ }^{4}$ UK Soil Survey Classification.

the lysimeter station. All lysimeters were under permanent grass during the experiment.

The second study ("Ultuna 2") comprises tracer experiments using chloride-36 conducted in 1990 on one soil taken from a site in southern Sweden (Mellby soil; Bergström et al. (1994). Chloride-36 was applied in mid-June 1990 to replicate lysimeters planted with spring barley (Hordeum distichum $L$.). The lysimeter station was located at Ultuna, Uppsala, and is described in detail by Bergström (1992).

The third study ("Ultuna 3") comprises tracer experiments conducted on replicate lysimeters taken from a structured clay soil (Lanna) and a sand (Nåntuna), presented in Bergström et al. (2011). Bromide was applied 18 Oc- tober 2006 to replicate lysimeters, and leachate was collected during two years. All lysimeters, which were placed in the lysimeter station at Ultuna, were cultivated with spring barley, and harvested early September.

The fourth study includes two lysimeters, from the same soil type, and was based on a bromide tracer experiment conducted in Villamblain, in the "Petite Beauce" region, France $\left(48.01^{\circ} \mathrm{N}, 1.55^{\circ} \mathrm{E}\right)$, between 1996 and 1998. Soils were cultivated with winter wheat, maize, and winter wheat during the experiment, and bromide was applied at the end of January 1996. It was observed in this study that bromide had a negative effect on crop growth (but the effect was not quantified). 


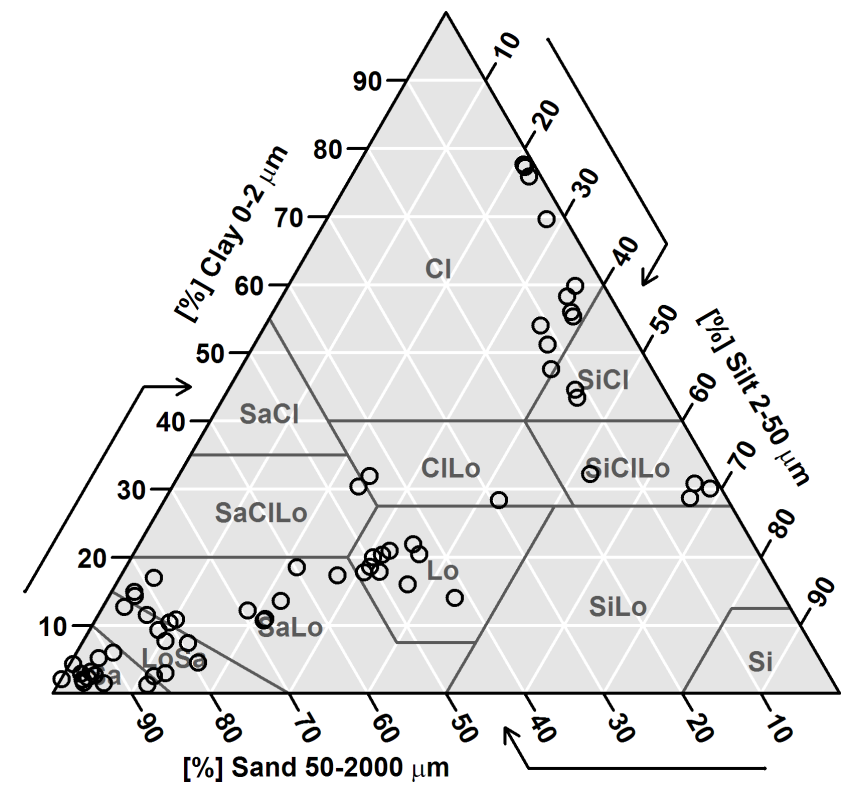

Fig. 1. Textures of the different horizons of the 16 soils used for our study, represented over USDA Soil Texture Triangle classes: "Cl" means "Clay" or "Clayey"; "Si" means "Silt" or "Silty"; 'Sa" means "Sand" or "Sandy"; and "Lo" means "Loam" or "Loamy".

The fifth study includes replicate lysimeters of five contrasting soils, from a leaching study conducted at Silsoe (UK, $52.0^{\circ} \mathrm{N}, 0.4^{\circ} \mathrm{W}$; Cuckney, Sonning, Ludford, Enborne and Isleham soils; Brown et al., 2000). All lysimeters were sown with winter wheat. Bromide was applied in November 1994, and leaching was monitored until April 1996.

The sixth study consists of one lysimeter study from the "Brimstone Farm dataset" (ADAS/IACR Rothamsted, Oxfordshire, UK; $51.65^{\circ} \mathrm{N}, 1.64^{\circ} \mathrm{E}$ ), described by Beulke et al. (2001). This study is shorter than the others, with bromide applied in mid-December 1994, and monitored until 23 January 1995 . It is also the only lysimeter study conducted with bare soil.

As shown in Fig. 1, the soil horizons of the 16 different soils cover a broad range of texture. Of the USDA textural classes, only "silt", "silt loam" and "sandy clay" are not represented. Organic carbon content in both topsoil and subsoil horizons ranges from 0 to $29 \%$, with a median value of $0.6 \%$ for all horizons, and $1.7 \%$ for topsoil horizons. Bulk density ranges from 0.55 to $1.87 \mathrm{~kg} \mathrm{dm}^{-3}$, with a median value of $1.45 \mathrm{~kg} \mathrm{dm}^{-3}$. The mean depth of the soil profiles is $1 \mathrm{~m}$.

The following data were available and were converted to a uniform format and units: date and time at which the leachate sample was collected; amount of leachate collected $(\mathrm{mm})$; solute mass applied and amount leached $\left(\mathrm{g} \mathrm{m}^{-2}\right.$, but note that the ${ }^{36}$ chloride used in the Mellby study was expressed in Becquerels). For the Villamblain and the Mellby datasets, only measurements interpolated on a daily basis were available.
Daily weather data were available for all four lysimeter stations (Table 1). MACRO needs rainfall [mm] and, to estimate potential evaporation with the Penman-Monteith equation, the daily minimum and maximum temperatures $\left[{ }^{\circ} \mathrm{C}\right]$, solar radiation $\left[\mathrm{W} \mathrm{m}^{-2}\right]$, vapour pressure $[\mathrm{kPa}]$ and wind speed $\left[\mathrm{m} \mathrm{s}^{-1}\right]$. When available, the estimated potential evapotranspiration was provided directly (for "Ultuna 2", Villamblain, Silsoe and Brimstone). Internally, MACRO converts daily rainfall data into hourly rainfall data. The daily rainfall amount is converted into a single rainfall event starting at midnight, and with a constant intensity. This intensity is constant all year round in MACRO. Here the default value $2 \mathrm{~mm} \mathrm{~h}^{-1}$ was used, as no information was available to estimate its local value.

Previous studies comparing measured and simulated water and solute transport in lysimeters were only available for Lanna clay and Nåntuna sand (Jarvis, 1991; Saxena et al., 1994). In both cases, the model used was MACRO and the model was calibrated on the measured dataset and some parameters were measured directly. Jarvis (1991) was able to successfully reproduce the measured water and solute breakthrough, and Saxena et al. (1994) also obtained good fits to the measured data, except during some weeks in winter, as a treatment of snowpack was not included in the model at that time. No goodness-of-fit statistic is available to compare with our simulations. It is worth noting that, in this study, we are using a different dataset for these two soils. Beulke et al. (2001) tested uncalibrated modelling on measurements made in Brimstone, but used a dataset of water and pesticide losses to drains at the plot scale. In their study, pesticide losses estimated by MACRO were in the same order of magnitude as the measurement.

\subsection{The MACRO model}

MACRO is a one-dimensional dual-permeability model of water flow and solute transport in macroporous soil. The water and solute are partitioned between two domains: micropores where equilibrium flow and transport occur, represented by the Richards equation and the convection-dispersion equation; and macropores where non-equilibrium gravitydriven flow occurs, represented by a kinematic wave equation. Water exchange between micropores and macropores is considered as an instantaneous "discharge" when the matrix becomes over-saturated, while exchange in the other direction is modelled as a diffusive process controlled by an effective diffusion pathlength, as a surrogate parameter for the geometry of soil structure (Gerke and van Genuchten, 1996). A detailed description of the model is given by Larsbo et al. (2005). We used MACRO version 5.2. 


\subsection{Initial and bottom boundary conditions}

Several options to describe the lower boundary condition are available in MACRO, but we only considered a zero tension seepage surface, where only downward flow is allowed, which is appropriate for the lysimeter experiments considered in this study. In all cases, the initial conditions in the lysimeter experiments were unknown, since neither water contents nor pressure heads were measured. We therefore considered water contents at the beginning of each simulation to be at equilibrium with a (virtual) water table at the bottom of the soil profile. A warm-up period of real weather data was then included between the beginning of the simulation and the time of tracer application (14 days for Brimstone, 91 days for Ultuna 2, 145 days for Villamblain, 77 days at Silsoe and about a year for Ultuna $1 \& 3$ ).

\subsection{MACRO model parameterisation with the FOOTPRINT estimation algorithms}

\subsubsection{Soil}

Sixteen simulations were set up in MACRO. This latest version includes a tool for calculating the FOOTPRINT PTFs for soil parameters in MACRO. These PTFs make use of basic soil properties (particle size distribution, stone and organic carbon contents, bulk density and $\mathrm{pH}$ ) and other information provided by the user (horizon designation according to FAO, tillage system, and land use) to estimate physical and hydraulic parameters in the model.

For the soil matrix, MACRO uses the van Genuchten (1980) water retention function. The parameters of this function (the shape parameters $\alpha, n$ and the saturated water content $\theta_{\mathrm{S}}$ ) were estimated using the continuous PTFs developed by Wösten et al. (1999) from the HYPRES database, considering $m=1-1 / n$ and that the residual water content $\theta_{\mathrm{R}}$ is zero. The saturated water content was corrected for stone content:

$\theta_{\mathrm{S}}=\theta_{\mathrm{S}(\mathrm{HYPRES})}\left(1-f_{\mathrm{S}}\left(1-\varepsilon_{\mathrm{S}}\right)\right)$

where $\theta_{\mathrm{S} \text { (HYPRES) }}\left[\mathrm{m}^{3} \mathrm{~m}^{-3}\right]$ is the saturated water content estimated with the HYPRES PTF, $f_{\mathrm{S}}$ is the volumetric fraction of stones in the soil $\left[\mathrm{m}^{3} \mathrm{~m}^{-3}\right]$ and $\varepsilon_{\mathrm{S}}$ is the stone porosity $\left[\mathrm{m}^{3} \mathrm{~m}^{-3}\right]$. As a unimodal function, the van Genuchten equation cannot reflect the effects of soil macropores on soil water retention. Thus, $\theta_{\mathrm{S}}$ is not used as a MACRO parameter. Instead, this "nominal" saturated water content is used together with $\alpha$ and $n$ to estimate the wilting point water content $(\theta$ at a pressure potential of $-150 \mathrm{~m})$ and $\theta_{\mathrm{S}(\mathrm{m})}$, the saturated water content in the soil matrix, when $\psi=\psi_{\mathrm{m}}$. The water potential defining the boundary between the micropores and the macropores, $\psi_{\mathrm{m}}$, was fixed at $-10 \mathrm{~cm}$, as suggested by a review of the literature (Jarvis, 2007). The saturated hydraulic conductivity of the soil matrix $K_{\mathrm{S}(\mathrm{m})}$ (i.e. soil hydraulic con-

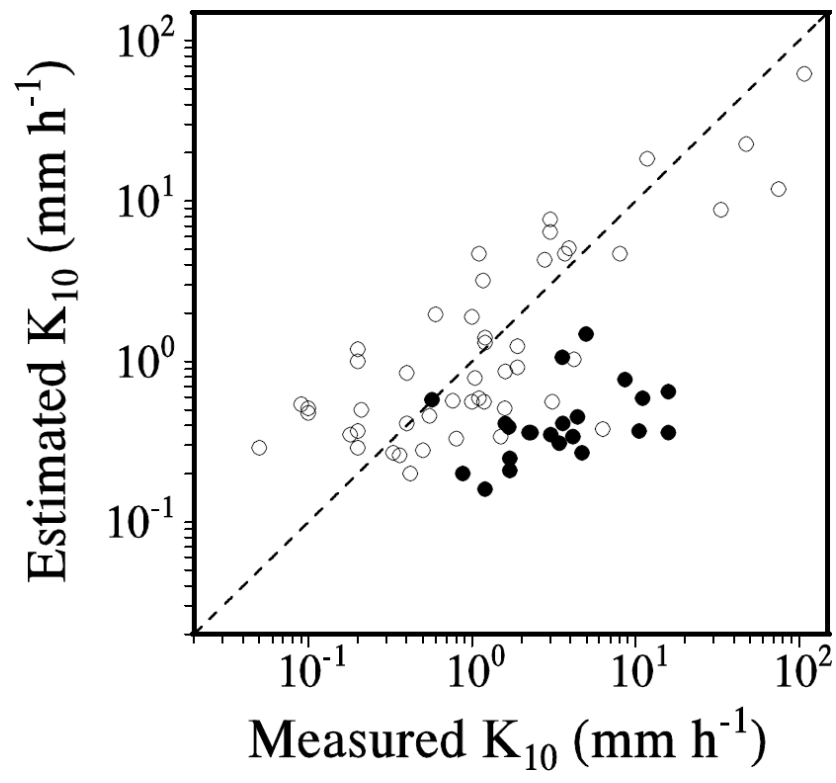

Fig. 2. Measured and predicted saturated matrix hydraulic conductivity. Data are taken from Jarvis et al. (2002). Predicted values are calculated using Eq. (2), and $\theta_{10}$ and $n$ are predicted by HYPRES. Solid symbols represent data obtained by three of the ten researchers.

ductivity at $\psi_{\mathrm{m}}$ ) is estimated with a new PTF:

$K_{\mathrm{S}(\mathrm{m})}=C \theta_{\mathrm{S}(\mathrm{m})} n^{l}$

where $C$ and $l$ are constants derived from experimental data from Jarvis et al. (2002) and set to $0.186 \mathrm{~mm} \mathrm{~h}^{-1}$ and $10.73[-]$, respectively. $\theta_{\mathrm{S}(\mathrm{m})}$ and $n$ are the water contents at $-10 \mathrm{~cm}$ and van Genuchten $n$ parameters as predicted using the Wösten et al. (1999) pedotransfer functions (actual measured values should not be used here). In Fig. 2, measured and predicted $K_{\mathrm{S}(\mathrm{m})}$ values are compared. The agreement must be considered satisfactory, considering the errors involved in predicting $n$ (Wösten et al., 1999) and also the errors involved in the measurement of $K_{\mathrm{S}(\mathrm{m})}$, not in the least because they were performed by ten different researchers (Jarvis et al., 2002). This is illustrated by the fact that the measurements from three of the researchers fall consistently below the 1:1 line (Fig. 2), despite the fact that they used the same method.

Parameters related to soil macropores are estimated by a combination of constants (parameters that do not vary with site or soil properties) and class and continuous PTFs. The volumetric macroporosity, $\varepsilon_{\mathrm{MA}}$, is determined with the class PTF presented in Table 3. This PTF was developed from expert judgement and is based on the USDA soil texture class, the FAO Master Horizon Designation and soil management practices. $\varepsilon_{\mathrm{MA}}$ is summed with $\theta_{\mathrm{S}(\mathrm{m})}$ to give the total soil porosity. The effective diffusion pathlength, $d$, that regulates exchange of water and solute between macropores and micropores and the kinematic exponent, $n^{*}$, that reflects 
Table 3. Lookup table for estimating macroporosity in MACRO (horizon designations are FAO Master Horizon Designations).

\begin{tabular}{llrrr}
\hline Soil & Horizon & \multicolumn{3}{c}{${ }^{1}$ Texture } \\
\cline { 3 - 5 } & & Fine & Medium & Coarse \\
\hline Topsoil & ${ }^{2}$ Undisturbed & & 0.050 & \\
(mineral) & ${ }^{3} A_{\mathrm{T}}$ ' & & 0.050 & \\
& ${ }^{4} A_{\mathrm{P}}$ & 0.030 & 0.040 & 0.050 \\
\hline Subsoil & ${ }^{5}$ Upper "B" or "E" & 0.160 & 0.160 & 0.050 \\
(mineral) & ${ }^{6}$ Lower "B" or "E" & 0.008 & 0.008 & 0.050 \\
& "BC' & 0.002 & 0.004 & 0.040 \\
& "C" & 0.002 & 0.004 & 0.030 \\
\hline Organic & "O" or "H" & & 0.050 & \\
\hline
\end{tabular}

1 "Fine" is clay, silty clay, silty clay loam in the USDA texture triangle; "Coarse" is sand and loamy sand; "Medium" is all other classes. ${ }^{2}$ Perennial crops, i.e. grassland, vines, orchards, olives. ${ }^{3}$ Intensively (secondary) tilled uppermost soil layer. ${ }^{4}$ Ploughed but not secondary tilled. ${ }^{5}$ Mid-point depth of horizon $<50 \mathrm{~cm}$. ${ }^{6}$ Mid-point depth of horizon $>50 \mathrm{~cm}$.

the size distribution, tortuosity and connectivity of macropores, and controls flow rate in the macropore domain are obtained from the class PTF presented in Table 4, which distinguishes four classes of susceptibility to macropore flow. The susceptibility to macropore flow of each horizon is determined with a decision tree, described in detail and successfully tested by Jarvis et al. (2009). The decision tree is based on USDA soil textural classes, FAO Master Horizon designations, tillage characteristics (no or reduced tillage, conventional tillage/ploughing or harrowing) and organic carbon content. The decision tree also makes use of a subsidiary decision tree to predict the abundance of large earthworm biopores (Lindahl et al., 2009) from soil climate, land use, texture class and the presence of limiting factors (such as horizons without pedogenetic features or with coarse texture, water tables, low $\mathrm{pH}$ and high bulk density). The MACRO parameter values associated with each class (Table 4) were set according to expert judgement based on extensive experience from calibrating and validating the model against experimental data (e.g. Jarvis, 2007; Köhne et al., 2009a, b).

A simple expression for macropore saturated hydraulic conductivity $K_{\mathrm{S}(\mathrm{MA})}$ can be derived from the "capillary bundle" model of soil macropore hydraulic properties described in Jarvis (2008):

$K_{\mathrm{S}(\mathrm{MA})}=\left(B \varepsilon_{\mathrm{MA}}\right) / n^{*}$

where " $B$ " is a composite "matching factor" accounting for both physical constants and the geometry of the functional macropore system, which was set to $6000 \mathrm{~mm} \mathrm{~h}^{-1}$.

Finally, as a special case, hydraulic parameters for permeable rock substrates ( $\mathrm{R}$ horizons, which in our study only occurred at the Villamblain site) are set to fixed values, assuming a high potential for macropore flow (i.e. class IV), as found by Roulier et al. (2006): $d=150 \mathrm{~mm} ; K_{\mathrm{S}(\mathrm{MA})}=30 \mathrm{~mm} \mathrm{~h}^{-1} ; K_{\mathrm{S}(\mathrm{m})}=0.04 \mathrm{~mm} \mathrm{~h}^{-1}$;
Table 4. Class pedotransfer functions for soil structure-related parameters. The preferential flow class is determined using the decision tree presented in Jarvis et al. (2009).

\begin{tabular}{|c|c|c|}
\hline $\begin{array}{l}\text { Macropore } \\
\text { Flow Class }\end{array}$ & $\begin{array}{l}{ }^{1} \text { Effective } \\
\text { Diffusion } \\
\text { Pathlength, } \\
d \text { [mm] }\end{array}$ & $\begin{array}{l}\text { Kinematic, } \\
\text { Exponent } \\
n^{*}[-]\end{array}$ \\
\hline I (none) & 1 & 6 \\
\hline II (weak) & 15 & 4 \\
\hline III (moderate) & 50 & 3 \\
\hline IV (strong) & 150 & 2 \\
\hline
\end{tabular}

${ }^{1}$ The effective diffusion pathlength $(d)$ is set to $3 \mathrm{~mm}$ in the uppermost intensively tilled layer in arable soil independent of class.

$\theta_{\mathrm{S}(\mathrm{m})}=0.1 \mathrm{~m}^{3} \mathrm{~m}^{-3} ; \alpha=0.0004 \mathrm{~cm}^{-1} ; n=1.8 ; n^{*}=2 ;$ $\varepsilon_{\mathrm{MA}}=0.01 \mathrm{~m}^{3} \mathrm{~m}^{-3}$.

\subsubsection{Crop}

Crop parameters were defined using the class estimation algorithms defined in FOOTPRINT (Jarvis et al., 2007). These estimation algorithms classify crops into nine groups of annual crops and three groups of perennial crops. The lysimeter studies were conducted under either bare soil, wheat, barley, maize or grass, which represent only three of these groups (Table 5). The crop parameters were chosen according to FOCUS (2001), except for parameters related to drought tolerance, which were chosen according to Allen et al. (1998). In the FOOTPRINT inference system, the crop-specific maximum rooting depth is reduced by the presence of limiting soil factors: "C" or " $\mathrm{R}$ " FAO master horizon designations; $\mathrm{pH} \leq 4.5$; USDA sand and loamy sand texture classes with less than $0.2 \%$ organic carbon; a stone content larger than $20 \%$ or a bulk density larger than $1.65 \mathrm{~kg} \mathrm{dm}^{-3}$ in the subsoil. The remaining crop parameters concern crop development stages. In FOOTPRINT, they are set according to a database of crop development stages available for each of sixteen climate zones in Europe. In this study, however, crop development stages such as emergence day and harvest day were set according to the observed dates in each lysimeter study.

\subsubsection{Solute}

Apart from the effective diffusion pathlength, solute transport parameters were set to constants (identical for all soils). The diffusion coefficient in water was set to $1.9 \times 10^{-9} \mathrm{~m}^{2} \mathrm{~s}^{-1}$. The mixing depth, which controls routing of solutes into macropores at the soil surface, was set to $1 \mathrm{~mm}$. Anion exclusion was not considered. The matrix dispersivity was set to $3.4 \mathrm{~cm}$, which is the mean value for a sub-set of 116 samples taken from the Vanderborght and Vereecken (2007) database, for experiments carried out at 
Table 5. Crop parameters in the FOOTPRINT inference system used in this study.

\begin{tabular}{lrrlrll}
\hline Parameters & \multicolumn{2}{c}{ Crop groups } & Parameters & Crop groups & Constant & all \\
\hline & A (Cereals) & $\mathrm{F}$ (Maize) & & Grass & Parameters & groups \\
\hline LAI $_{\text {Max }}$ & 5 & 5 & LAI $_{\mathrm{C}}$ & 5 & $x_{1}$ & 1.6 \\
LAI $_{\text {Har }}$ & 1 & 2 & & & $x_{2}$ & 0.3 \\
Drought tolerance & $65 \%$ & $65 \%$ & Drought tolerance & $65 \%$ & LAI $_{\text {Min_sp }}$ & 0.01 \\
$\beta$ & 0.2 & 0.2 & $\beta$ & 0.2 & LAI $_{\text {Min_sp }}$ & 1.0 \\
$R_{\max }$ & 1.1 & 1.1 & $R_{\text {Depth }}$ & 0.8 & $R_{\text {Init_sp }}$ & 0.01 \\
CANCAP & 2 & 3 & CANCAP & 2 & $R_{\text {Init_au }}$ & 0.2 \\
$Z_{\text {ALP }}$ & 1.0 & 1.5 & $Z_{\text {ALP }}$ & 1.0 & CR $_{\text {Air }}$ & 0.05 \\
\hline
\end{tabular}

$\mathrm{LAI}_{\mathrm{Max}}$ is the maximum leaf area index; $\mathrm{LAI}_{\mathrm{Har}}$ is the green leaf area index at harvest; "Drought tolerance" is the \% of extractable micropore water exhausted before reduction in transpiration occurs, and it is used to calculate the critical tension for transpiration reduction (WATEN); $\beta$ is the transpiration adaptability factor; $R_{\max }$ is the maximum root depth [m]; CANCAP is the maximum interception capacity [mm]; $Z_{\mathrm{ALP}}$ is the ratio evaporation of intercepted water to transpiration; $\mathrm{LAI}_{\mathrm{C}}$ is the leaf area index of permanent crops; $R_{\text {Depth }}$ is the root depth for permanent crops. $x_{1}$ and $x_{2}$ are the leaf development factor, for growth and senescence, respectively; LAI $\mathrm{Min}_{\text {_sp }}$ and LAI $\mathrm{I}_{\mathrm{Min} \_a u}$ are the leaf area index on specified day for spring and autumn crops, respectively; $R_{\text {Init sp }}$ and $R_{\text {Init au }}$ are the root depth on the intermediate crop development stage between emergence and maximum leaf area for spring and autumn crops, respectively; $\mathrm{CR}_{\mathrm{Air}}$ is the critical air content for transpiration reduction $\left[\mathrm{m}^{3} \mathrm{~m}^{-3}\right]$.

steady flow rates of less than $1 \mathrm{~mm} \mathrm{~h}^{-1}$, which should exclude the influence of dispersion due to macropore flow. As macropore flow is explicitly accounted for in MACRO, and results in a higher apparent dispersivity, it is necessary to exclude its influence when estimating matrix dispersivity. Finally, the fraction of solute taken up by crop roots with the water was set to 1 (i.e. completely passive uptake).

\subsection{Analyses of modelling results}

\subsubsection{Bulking replicated measurements}

Water outflow and solute leaching were in most cases measured in several replicate lysimeters of the same soil. However, only one set of average physico-chemical properties was available for each soil type. Thus, only one set of MACRO parameters and one prediction could be obtained for each soil type. As a consequence, the measurements include a local variability that simulations cannot reflect. To overcome this, we bulked the replicated measurements for each soil type and calculated average measured water and solute outflows to allow sound statistical comparisons of measurements and simulations.

Before any analysis of the results, the amount of water drained at the outlet of lysimeters was transformed into pore volumes. This non-dimensional unit allows comparing the amount of water leached in soil profiles with different properties. Sensu stricto pore volumes should be calculated as the amount of water drained divided by the product of water content and soil profile height. As no information was available on soil profile water contents, we have instead considered pore volumes as the amount of water drained divided by the product of porosity and soil profile depth. The porosity of each horizon was calculated from the horizon bulk density and an estimated particle density.

\subsubsection{Statistical measures of model "goodness of fit"}

We assessed the agreement between measured and simulated water flows with the Nash-Sutcliffe model efficiency (Schaefli and Gupta, 2007; Nash and Sutcliffe, 1970):

$\mathrm{NSE}=1-\frac{\sum_{t=1}^{n}\left(x_{\mathrm{obs}, t}-x_{\mathrm{sim}, t}\right)^{2}}{\sum_{t=1}^{n}\left(x_{\mathrm{obs}, t}-\bar{x}_{\mathrm{obs}, t}\right)^{2}}$

where $x_{\mathrm{obs}, t}$ and $x_{\mathrm{sim}, t}$ are the $t$-th observed and simulated values, respectively.

In contrast to tracers, pesticides are degraded. Because of this, we are most interested in the ability of the model to reproduce early tracer breakthrough. Accurate prediction of early solute breakthrough is dependent on the ability of the model to accurately simulate water flows soon after solute application. This in turn requires knowledge of the initial hydrological conditions, which in our case were unavailable. We have thus compared simulated and measured accumulated amounts of solute leached (expressed as a fraction of the applied amount) at $0.1,0.2$ and 0.3 pore volumes (PV) of water drained. These values were chosen because (1) not all lysimeter experiments had more than 0.3 pore volumes drained, (2) peak solute leaching occurs before 1 pore volume of drainage in soils exhibiting preferential flow or large dispersion and (3) the half-lives of most registered pesticides are much shorter than the time required for 1 pore volume of water to pass through a one-meter soil profile, even in relatively wet climates. Preferential solute leaching is "event-driven", which makes the Nash-Sutcliffe model efficiency very sensitive to even slight errors in timing. Nolan et al. (2009) proposed a "refined lack-of-fit statistic" that measures the ability of a model to predict peak concentrations and takes into account possible shifts in time (and scale). It is unfortunately not easily applicable here, as not all our simulations exhibit clearly defined solute leaching peaks. We 
therefore assessed the agreement between measured and predicted accumulated solute loads at 0.1, 0.2 and 0.3 PV with the concordance correlation coefficient (Lin, 1989), referred to here as CCC, an estimator that takes into account both scale and location departure from the one-to-one measured versus predicted line (i.e. a systematic bias or a high dispersion, respectively). We have used the CCC calculation implemented in the R package epiR (Stevenson et al., 2009; R. Development Core Team, 2011). The formula of the CCC for two variables $x$ and $y$ is

$\hat{\rho}_{C}=\frac{2 S_{x y}}{S_{x}^{2}+S_{y}^{2}+(\bar{x}-\bar{y})^{2}}$

with $\quad S_{j}^{2}=(1 / n) \sum_{i=1}^{n}\left(j_{i}-\bar{j}\right)^{2}, j=x, y \quad$ and $\quad S_{x y}=$ $(1 / n) \sum_{i=1}^{n}\left(x_{i}-\bar{x}\right)\left(y_{i}-\bar{y}\right)$ and $n$ the number of samples.

The ability of the model to accurately predict water outflow and solute loads is particularly important in the context of registration and risk assessment, because the leachate concentration is a key "end-point". For risk management, an alternative criterion to the absolute concentration would be whether the model correctly identifies the sources of diffuse pollution in the landscape (i.e. to identify appropriate mitigation measures). It is then no longer absolute values that are important, but rather the ranking of soil types with respect to solute leaching. We have thus also computed the ranking of each soil according to the measured and predicted accumulated solute loads at $0.1,0.2$ and 0.3 pore volumes and calculated the CCC on these ranks.

\subsubsection{Benchmarking: does macropore flow matter?}

Statistical measures of the agreement between measured and simulated time series variables, such as the Nash-Sutcliffe model efficiency, may be difficult to interpret. Seibert (2001) recommended "benchmarking" predictions against a simpler model, to assess the relative improvement provided by a more complex model. In this study, we compare predictions of the full model with MACRO simulations parameterized in such a way that macropore flow is eliminated. This is done by setting the effective diffusion pathlength to $1 \mathrm{~mm}$, which ensures extremely rapid equilibration between the two flow domains. This effectively reduces the dual-permeability model to a single-domain flow and transport model (the Richards equation coupled to the advection-dispersion equation). In this way, we can test whether the uncertainty in estimating macropore flow parameters by pedotransfer functions outweighs the errors in model predictions introduced by neglecting macropore flow.

\subsection{Calibration}

A simple way to assess parameterisation errors is to perform a calibration of the model parameters, by testing different parameter sets and comparing them to the measured values (inverse modelling). The extent to which calibrated parameter sets improve the modelling, as compared to non-calibrated simulations, gives us an idea of how good or bad the base parameterisation is. It helps us to know which parameters should be better predicted to achieve better simulations. The strategy is nevertheless somewhat limited, because, (a) due to resource limitations, it was not possible for us to calibrate all the important MACRO parameters, and (b) several parameters may have similar impacts on water flow or solute transport, which leads to equifinality (Beven, 1993).

The calibration procedure was conducted in two steps. Two parameters were calibrated in the first step to improve water flow modelling, and two other parameters were calibrated in the second step to improve solute transport modelling.

\subsubsection{Calibrating crop parameters that impact the water balance}

A first analysis of the results revealed that simulations of water outflows could be improved with a better parameterisation of some crop parameters. The maximum root depth $R_{\max }$ and the uptake compensation factor $\beta$, which reflects crop drought tolerance, were optimised because of their expected impact on the overall water balance (i.e. because they are both sensitive and uncertain). When $\beta$ is 1 , there is no water uptake compensation, and when $\beta$ is 0 , there is a complete compensation. Five values of $R_{\max }$ were tested, from 0.30 to $1.10 \mathrm{~m}$ (or to the lysimeter depth if the lysimeter was shorter), and five values of $\beta$ (from 0 to 1 ), giving 25 different parameter combinations.

Additional changes were made to the parameterisation of the "Ultuna 1" lysimeters. For practical reasons, the FOOTPRINT estimation algorithms consider grass as a perennial crop. This means that, for the non-calibrated simulations, the root depth and leaf area are constant all the year round, and MACRO simulates crop transpiration as soon as temperatures rise above zero. But grass growing in Nordic countries (and elsewhere) is affected by winter frost burns, and its green leaf area gradually decreases in the autumn, and gradually increases in the spring, when temperatures are above $6^{\circ} \mathrm{C}$ (Persson, 1997). For this reason, in the calibrated simulations, the grass in the Ultuna lysimeters has been considered as an annual crop, with an annual cycle of leaf area development (emergence on day 364, a linear increase of leaf area until day 90, maximum leaf area on day 180 and "harvest" on day 363).

The optimal parameter combination was chosen as the one with the best Nash-Sutcliffe model efficiency. This was calculated on accumulated water outflow rather than outflows for each sampling period, since the results were then less sensitive to periods where some water flow is predicted by MACRO while the measured water flow is zero, or vice versa. 

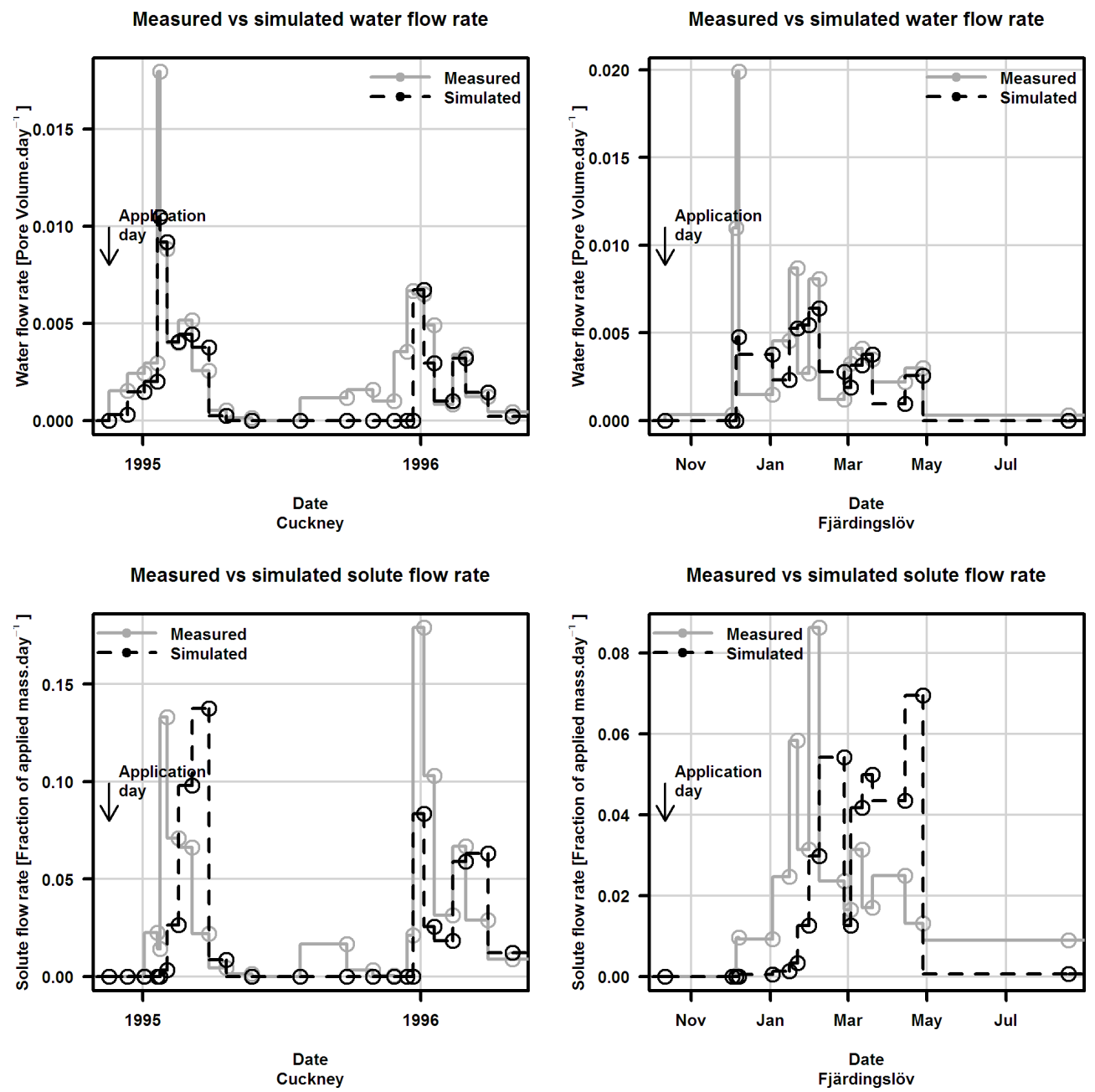

Fig. 3. Examples of measured versus simulated water and solute flows, for one soil that is "rather well" simulated (Cuckney) and one that is "rather poorly" simulated (Fjärdingslöv). Solid lines are measured values and dashed lines are simulated values.

\subsubsection{Calibrating solute transport}

Based on the calibrated simulations of water outflow, a second optimisation was conducted for solute transport. Preliminary tests showed that the extent of solute uptake by the crop was an important determinant of the overall tracer balance. In a few cases, we also noted that, while the water balance was well simulated, the simulated bulk matrix solute transport was apparently slower than the measured (see Sect. 3.1). For this reason, we also optimised the anion exclusion factor in the model $\left(\theta_{\mathrm{ae}}\right)$. Internally, MACRO defines a "mobile water content" $\left(\theta_{\mathrm{mi}(\mathrm{m})}\right)$ that is calculated as $\theta_{\mathrm{mi}(\mathrm{m})}=\theta_{\mathrm{mi}}-\theta_{\mathrm{ae}}$, if $\theta_{\mathrm{ae}}<\theta_{\mathrm{mi}}$ and $\theta_{\mathrm{mi}(\mathrm{m})}=0$ if $\theta_{\mathrm{ae}} \geq \theta_{\mathrm{mi}}$ (Larsbo and Jarvis, 2003 , p. 29). Anion exclusion is not the only process that can explain fast solute transport in the matrix. The presence of immobile water and heterogeneous flow in the matrix may produce similar effects. To some extent, it should be possible to account for this by calibrating the matrix dispersivity, but the lack of resident concentration data and thus the likelihood of equifinality persuaded us to keep the analysis simple and focus only on anion exclusion. Five values of the solute uptake concentration factor (from 0 to 1 ) and ten values of the anion exclusion factor were tested (from 0 to the water content at wilting point). This gave 50 different parameter combinations. The optimal parameter combination (from the 50 tested) was chosen as the one with the best model efficiency on time series of accumulated solute leaching.

\section{Results and discussion}

\subsection{Uncalibrated modelling}

Model efficiencies for water flow are given in Table 6. For uncalibrated simulations, the median efficiencies are 0.42 for water outflows and 0.67 for the accumulated water outflows respectively, but large differences existed between lysimeters. Figure 3 gives an example of an experiment that is rather well simulated (Cuckney), and one that is rather 

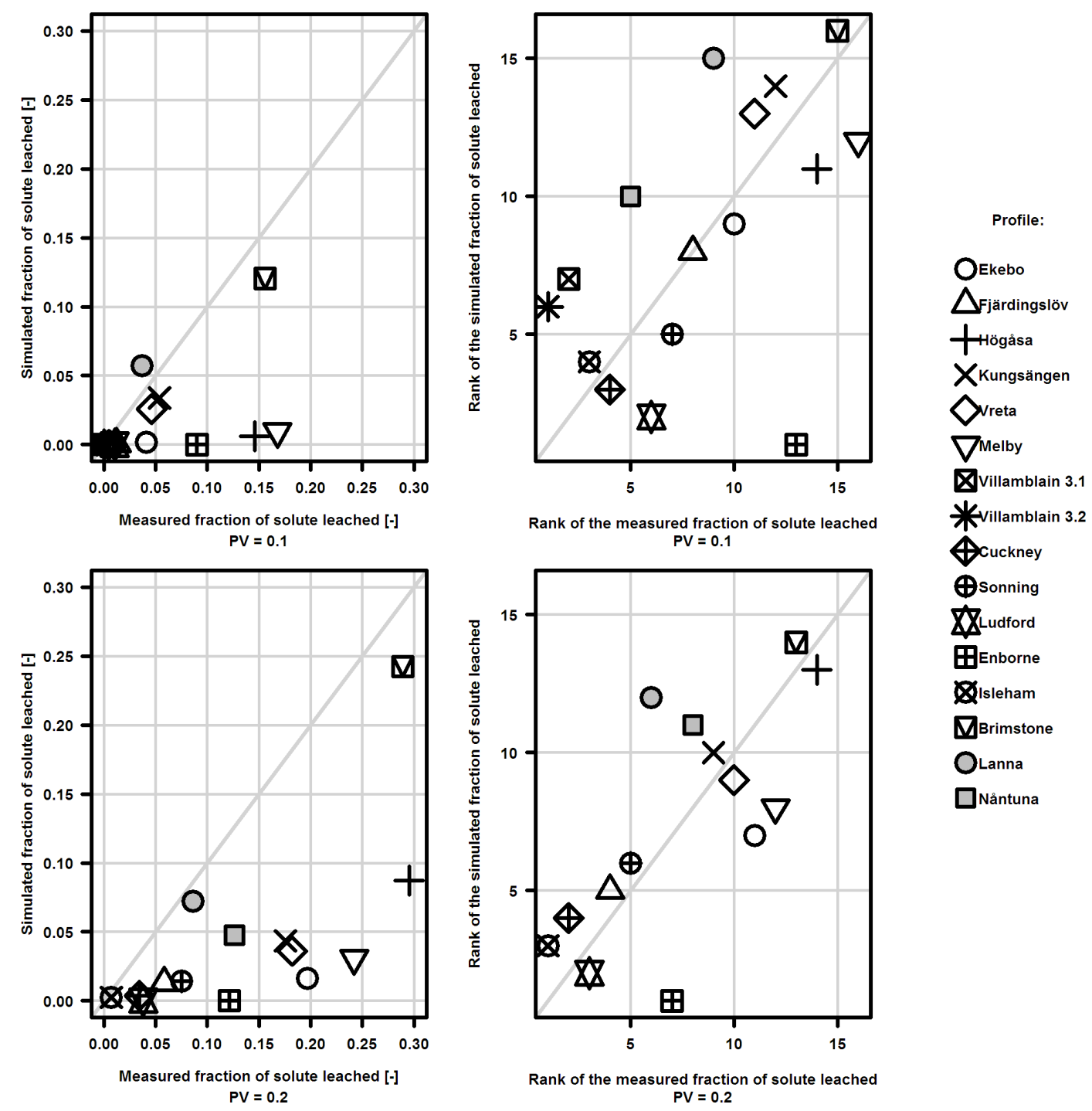

Fig. 4. Left part: measured versus simulated accumulated solute loads leached at 0.1 (upper part) and 0.2 (lower part) pore volumes (PV), expressed as a fraction of the applied solute [-]. Right part: soil ranks according to the same criterion. At 0.2 pore volume, Villamblain 1 and 2 soils are not represented, because neither the simulation nor the measurements reached that pore volume.

poorly simulated (Fjärdingslöv). In the Supplement, Table S1 presents the total rainfall amount, percolation and evapotranspiration for each non-calibrated simulation, and Figs. S1 to S16 present their simulated and measured water and solute flow. While most English soils were well simulated, the Villamblain soil and some Swedish soils were not. Model efficiencies were low in Högåsa and Mellby soils, for instance, but very good for Enborne and Brimstone. Visual examination of the bulked simulation results for each soil type (see the Supplement) revealed that the model sometimes failed to reproduce the first peak of water outflow, especially for the experiments conducted at Silsoe, but also for some of the Swedish soils (e.g. Fjärdingslöv, see Fig. 3). This is probably due to the lack of measured data to identify the correct initial condition in the simulation (Zehe et al., 2007).
In other cases (Vreta, Mellby), the total drainage was sometimes overestimated, presumably due to an underestimation of transpiration. For the Isleham peaty soil and Kungsängen, the water flow was accurately modelled the first year, but not the second year.

Figure 4 shows measured versus simulated solute leaching at 0.1 and 0.2 pore volumes, expressed in absolute terms and as ranks, respectively. The trends observed at 0.3 pore volumes are similar to those seen at 0.2 pore volumes (although comparisons are made for only 11 soils) and are therefore not shown. It is striking that the simulated solute load leached at 0.1 and 0.2 pore volume was systematically underestimated (CCC $=0.33$ and 0.35 , respectively). Although not as strongly underestimated, solute load was still not well simulated at 0.3 pore volumes $(\mathrm{CCC}=0.50)$. If the comparison 
Table 6. Model efficiencies of simulated water flow (WF), accumulated water volume (WC), solute load (SL) and accumulated solute load (SL), without calibration, and with 2 water-related crop parameters ( $\beta$ and $R_{\max }$ ) and 2 solute-related parameters (solute uptake concentration and anion exclusion factors) optimized. The differences in model efficiency between the 2 methods are also given. Model efficiencies were calculated after averaging replicated measurements, on the complete time series.

\begin{tabular}{|c|c|c|c|c|c|c|c|c|c|c|c|c|}
\hline \multirow[b]{2}{*}{ Soil profile } & \multicolumn{4}{|c|}{ No calibration } & \multicolumn{4}{|c|}{ Crop/water parameter calibrated } & \multicolumn{4}{|c|}{ Differences } \\
\hline & WF & WC & SL & SC & WF & WC & SL & $\mathrm{SC}$ & WF & WC & SL & SC \\
\hline Ekebo & 0.41 & 0.97 & -0.28 & -0.10 & 0.07 & 0.97 & -0.16 & 0.89 & -0.34 & 0.00 & 0.12 & 0.99 \\
\hline Fjärdingslöv & -0.03 & 0.89 & -0.68 & 0.55 & 0.81 & 0.98 & -0.99 & 0.78 & 0.84 & 0.09 & -0.31 & 0.23 \\
\hline Högåsa & -3.94 & -1.39 & -2.83 & 0.00 & -3.66 & -1.04 & -2.52 & 0.12 & 0.28 & 0.35 & 0.31 & 0.12 \\
\hline Kungsängen & 0.14 & 0.67 & -0.79 & -0.36 & 0.15 & 0.86 & -2.27 & 0.77 & 0.01 & 0.19 & -1.48 & 1.13 \\
\hline Vreta & -1.12 & 0.90 & -0.64 & -0.44 & -0.73 & 0.94 & -0.33 & 0.82 & 0.39 & 0.04 & 0.31 & 1.26 \\
\hline Mellby & -1.24 & -3.23 & -0.40 & -1.13 & -1.24 & -3.23 & -0.65 & 0.68 & 0.00 & 0.00 & -0.25 & 1.81 \\
\hline Lanna & 0.66 & 0.96 & -0.02 & -2.00 & 0.67 & 0.97 & 0.19 & 0.64 & 0.01 & 0.01 & 0.21 & 2.64 \\
\hline Nåntuna & 0.59 & 0.91 & -0.10 & 0.82 & 0.65 & 0.98 & 0.01 & 0.87 & 0.06 & 0.07 & 0.11 & 0.05 \\
\hline Villamblain & -0.11 & -0.79 & -0.05 & -0.99 & -0.25 & 0.69 & -0.22 & 0.32 & -0.14 & 1.48 & -0.17 & 1.31 \\
\hline Villamblain & -0.04 & -1.08 & -0.10 & -1.14 & 0.1 & 0.17 & -1.52 & 0.2 & 0.14 & 1.25 & -1.42 & 1.34 \\
\hline Cuckney & 0.62 & 0.48 & -0.01 & 0.59 & 0.75 & 0.79 & -0.3 & 0.84 & 0.13 & 0.31 & -0.29 & 0.25 \\
\hline Sonning & 0.42 & 0.67 & -0.22 & 0.75 & 0.67 & 0.89 & -0.37 & 0.88 & 0.25 & 0.22 & -0.15 & 0.13 \\
\hline Ludford & 0.51 & 0.48 & -0.94 & 0.47 & 0.57 & 0.75 & -1.32 & 0.68 & 0.06 & 0.27 & -0.38 & 0.21 \\
\hline Enborne & 0.77 & 0.88 & -0.24 & -2.77 & 0.84 & 0.92 & -1.46 & -1.13 & 0.07 & 0.04 & -1.22 & 1.64 \\
\hline Isleham & 0.71 & 0.31 & -0.28 & -0.62 & 0.71 & 0.31 & -0.23 & -0.33 & 0.00 & 0.00 & 0.05 & 0.29 \\
\hline Brimstone & 0.77 & 0.98 & 0.69 & 0.90 & 0.77 & 0.98 & 0.53 & 0.97 & 0.00 & 0.00 & -0.16 & 0.07 \\
\hline
\end{tabular}

is made on rankings, the results are much better (Fig. 4), although still far from being perfect $(\mathrm{CCC}=0.54,0.72$ and 0.65 for $\mathrm{PV}=0.1,0.2$ and 0.3 , respectively). The systematic underestimation of the amount of solute leached at 0.1 and 0.2 pore volumes may be explained by an underestimation of macropore flow intensity by our parameterisation algorithms. It may also be explained by the internal conversion of daily rainfall data into hourly rainfall data. The default average rainfall intensity we have used $\left(2 \mathrm{~mm} \mathrm{~h}^{-1}\right)$ may be inappropriate, as intense rainfall events are more likely to generate preferential flow, and thus early solute breakthrough (McGrath et al., 2009).

\subsection{Effect of calibration}

Table 6 shows, as expected, that calibrating two parameters controlling water uptake by crops improved significantly the simulations of water flows for those cases where results were poor without calibration (e.g. the Fjärdingslöv, Högåsa, Kungsängen and Vreta soils in Sweden and Cuckney, Sonning and Ludford soils in the UK). In the case of Ekebo and one of the Villamblain lysimeters, the simulation of water flow became worse after the calibration (Table 6). This is because the best parameter combination was chosen according to the model efficiency calculated on accumulated water outflows. It is also quite clear that modelling grass as an annual crop rather than a perennial (the default in the crop estimation algorithms) better corresponds to Swedish conditions. In several cases, improving the simulation of water outflows also improved the simulation of solute leaching (Table 6). But in other cases, the simulations became worse. Figures 5 and 6 show the effect of the calibration procedure on the concordance correlation coefficients between measured and simulated solute loads and ranked solute loads at $0.1,0.2$ and 0.3 pore volumes. It is clear from these figures that calibrating the two crop parameters only marginally improved the modelling of solute transport.

Calibration of both water uptake and solute transport parameters improved the simulation results for absolute loadings (Fig. 5), but only marginally improved the predictions of the ranking of soils according to the fraction of solute leached at different pore volumes (Fig. 6). The predicted ranking is even slightly worse at 0.3 pore volumes. This is due to the fact that the calibration was done on the complete breakthrough curve, and not just on the solute load at a given pore volume.

\subsection{Significance of calibration}

Calibrated values for $R_{\max }$ were significantly smaller than the values estimated from the lookup tables for nine lysimeters (from 0.3 to $0.5 \mathrm{~m}$ instead of $1.1 \mathrm{~m}$ ), and slightly smaller (around $0.8 \mathrm{~m}$ instead of $1.1 \mathrm{~m}$ ) for four lysimeters. We do not know whether or not this reflects a real problem with the estimation of $R_{\max }$, an artefact due to the experimental setting, or that calibrated values compensate for errors in other parameters that are important for water flow. The change in $R_{\max }$ does not appear related to soil properties. 


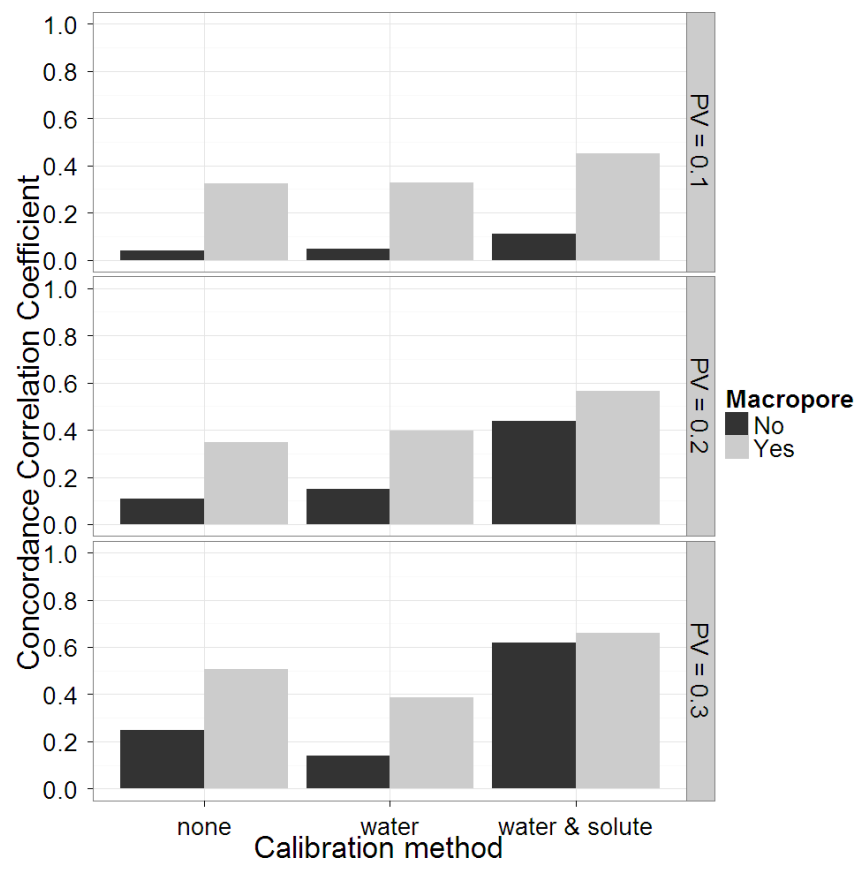

Fig. 5. Concordance correlation coefficient (CCC) of measured versus simulated accumulated solute loads leached at $0.1,0.2$ and 0.3 pore volumes for different calibration methods: no calibration (only pedotransfer functions); after calibration of 2 water-related crop parameters; after calibration of 2 additional solute-related crop and soil parameters. Darker bars represent simulations where solute macropore flow has been "switched-off", and grey bars represent (standard) simulations where macropore flow parameters have been parameterised according to the pedotransfer functions. Some soil profiles are not included in the CCC calculation at 0.2 and 0.3 pore volumes, because not all the lysimeters had this much drainage.

The calibrated $\beta$ parameter was higher than the values estimated from the lookup tables in nine lysimeters (from 0.5 to 1 instead of 0.2), and lower in seven (0 instead of 0.2). Again, no relationship was found between this change and soil properties, or with the change in $R_{\max }$, despite the fact that $\beta$ and $R_{\max }$ may have similar effects on the water balance.

In nine lysimeters, solute transport was improved if the fraction of tracer taken up by the crop was decreased (to 0.5 or 0 ), but this finding could not be related to any soil properties. The results are more interesting for anion exclusion, which was set to zero in the parameter scheme without calibration. Most simulations were improved when the excluded water content was increased (less than $10 \%$ for seven soils, and more than $10 \%$ for eight others, with a maximum value of $20 \%$ ). The estimated "optimal" values of the excluded water content were strongly correlated with clay content $\left(R_{\text {Pearson }}=0.86\right)$ and the estimated water content at wilting point $\left(\theta_{\mathrm{WILT}} ; R_{\text {Pearson }}=0.90\right)$, with an average value equal to $0.55 \theta_{\text {WILT }}$. Although we had bounded the range of possible values for the excluded water content between 0 and $\theta_{\text {WILT }}$, we think this result reflects a real trend of

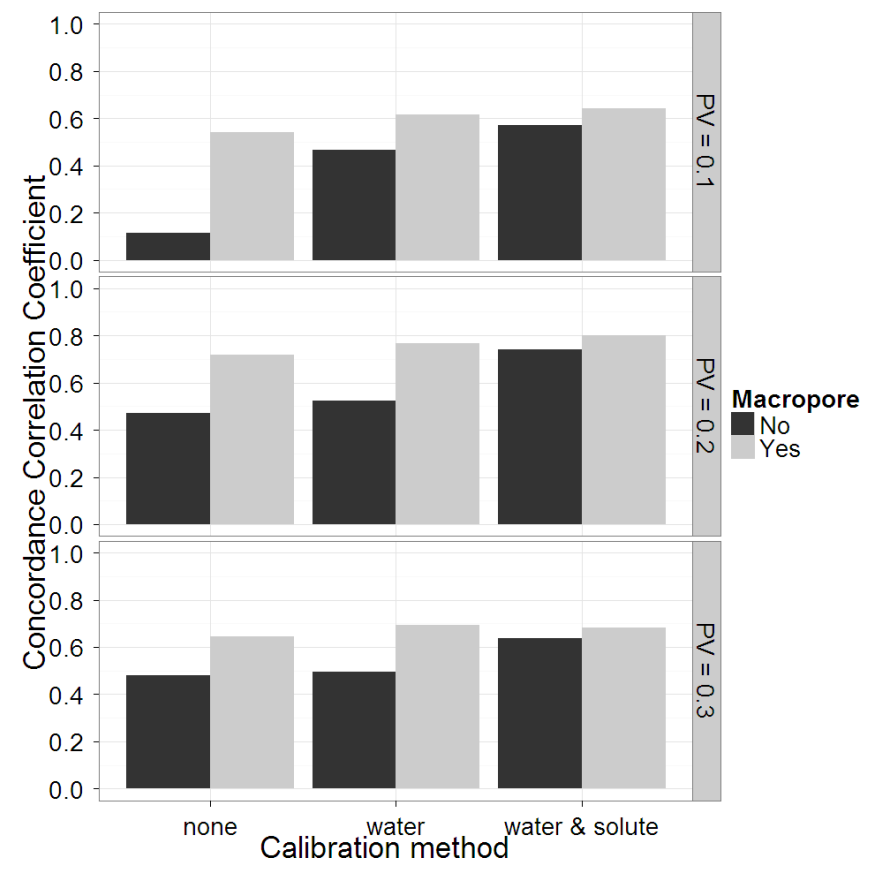

Fig. 6. Concordance correlation coefficient of the measured versus simulated soil ranks according to the accumulated solute loads leached at $0.1,0.2$ and 0.3 pore volumes for different calibration methods: no calibration (only pedotransfer functions); after calibration of 2 water-related crop parameters; after calibration of 2 additional solute-related crop and soil parameters. Darker bars represent simulations where solute macropore flow has been switchedoff, and grey bars represent (standard) simulations where macropore flow parameters were set according to the pedotransfer functions. Some soil profiles are not included in the CCC calculation at 0.2 and 0.3 pore volumes, because not all the lysimeters had this much drainage.

either faster bulk transport of the tracer in soils with more clay (and thus a higher $\theta_{\text {WILT }}$ ) due to anion exclusion or mobile-immobile preferential flow in the soil matrix. Alletto et al. (2006) found, for example, rather large immobile water contents $\theta_{\text {im }} / \theta$ (up to $90 \%$ ) in soils very similar to those of Villamblain.

\subsection{Does macropore flow matter?}

Figures 5 and 6 clearly show that, despite the additional uncertainties involved in simulating macropore flow, neglecting this process leads to worse predictions, especially at $0.1 \mathrm{PV}$ without calibration. This result is worth noting considering that not all soils may be prone to preferential flow. Overall, the effect of preferential flow is significant, despite the fact that it may be negligible in some lysimeters. Additionally, not all weather data series include rainfall events likely to trigger preferential flow, especially in the critical period soon after solute application (McGrath et al., 2009). The results also show that calibration of water uptake and solute transport parameters can partly compensate 
for neglecting macropore flow at later times $(\mathrm{PV}=0.2$ and 0.3 , see Figs. 5 and 6 ).

\section{Conclusions}

Predicting solute transport, and especially early solute breakthrough due to preferential flow, without measuring any model parameters and without calibration, is a challenge. Nonetheless, although model efficiencies were quite low, we consider our results promising, considering how variable and non-linear water and solute transport can be, especially in the presence of macropore flow. Overall, our results show that we generally strongly underestimate the amount of solute leached in the first 0.3 pore volumes drained. We cannot say whether this is due to model structural errors or parameter errors, but previous experience with MACRO has not indicated any systematic tendency to underestimate the strength of macropore flow (Köhne et al., 2009a, b), which suggests that the latter probably dominated. Also, we cannot completely exclude the influence of measurement errors. For example, some side-wall flow may have occurred in some lysimeters and disturbance to the structure caused during their extraction may have accelerated transport. Root development may also be limited or influenced by the lysimeter wall and the bromide tracer may also be toxic to crops when applied at high concentrations (Flury and Papritz, 1993; Observations on Villamblain lysimeters). Despite the fact that preferential flow was not expected in all soils and climate series, we show that not accounting for this process strongly and negatively affects the modelling results. Clearly, ignoring preferential flow can lead to strong biases in spatial patterns of solute leaching predicted at large scales. This conclusion stresses the importance of preferential flow in soils, and the need for improved pedotransfer functions to estimate preferential flow parameters. Finally, although the absolute values of solute leaching were poorly predicted by the model, the ranking of soil types according to this variable was generally much more reliable and was not greatly improved by calibration. This finding shows that the results from blind parameterisation of the MACRO model can be used to assess the relative vulnerability of soils to solute leaching in catchment and regional-scale assessments.

\section{Supplementary material related to this article is available online at: http://www.hydrol-earth-syst-sci.net/ 16/2069/2012/hess-16-2069-2012-supplement.pdf.}

Acknowledgements. This work has been funded by the FP6 EU-funded FOOTPRINT project (022704 SSP) and by CKB, the Centre for Chemical Pesticides at the Swedish University of Agricultural Sciences. The authors want to thank Helena Andersson for providing measured properties for the Lanna and Nåntuna soils, Per Nyman for making available Ultuna weather data series (Table 1), and Fredrik Stenemo for his help with MACRO 5.2 tools. The Villamblain experiment was initiated by the late Pierre Vachier, who pioneered vadose zone studies in France in the 1980's. His friendship will be greatly missed.

Edited by: M. Vanclooster

\section{References}

Allen, R. G., Pereira, L. S., Raes, D., and Smith, M.: Crop evapotranspiration - guidelines for computing crop water requirements, Irrig. Drain., 56, 15 pp., 1998.

Alletto, L., Coquet, Y., Vachier, P., and Labat, C.: Hydraulic Conductivity, Immobile Water Content, and Exchange Coefficient in Three Soil Profiles, Soil Sci. Soc. Am. J., 70, 1272-1280, doi:10.2136/sssaj2005.0291, 2006.

Bergström, L.: A Swedish lysimeter test system suitable for studying fate and behaviour of pesticides in soils, in: Lysimeter studies of the fate of pesticides in the soil, BCPC Monograph 53, edited by: Führ, F. and Hance, R. J., British Crop Protection Council, Farnham, UK, 1992.

Bergström, L., Jarvis, N., and Stenström, J.: Pesticide leaching data to validate simulation-models for registration purposes, J. Environ. Sci. Health Part A-Environ. Sci. Eng. Toxic Hazard. Subst. Control, 29, 1073-1104, 1994.

Bergström, L., Börjesson, E., and Stenström, J.: Laboratory and Lysimeter Studies of Glyphosate and Aminomethylphosphonic Acid in a Sand and a Clay Soil, J. Environ. Qual., 40, 98-108, doi:10.2134/jeq2010.0179, 2011.

Bergström, L. F. and Jarvis, N. J.: Leaching of dichlorprop, bentazon, and $\mathrm{Cl}-36$ in undisturbed field lysimeters of different agricultural soils, Weed Sci., 41, 251-261, 1993.

Beulke, S., Brown, C. D., Dubus, I. G., and Harris, G.: Evaluation of uncalibrated preferential flow models against data for isoproturon movement to drains through a heavy clay soil, Pest Manag. Sci., 57, 537-547, 2001.

Beven, K.: Prophecy, reality and uncertainty in distributed hydrological modeling, Adv. Water Resour., 16, 41-51, doi:10.1016/0309-1708(93)90028-e, 1993.

Boesten, J. J. T. I.: Modeller subjectivity in estimating pesticide parameters for leaching models using the same laboratory data set, Agr. Water Manage., 44, 389-409, 2000.

Brown, C. D., Hollis, J. M., Bettinson, R. J., and Walker, A.: Leaching of pesticides and a bromide tracer through lysimeters from five contrasting soils, Pest Manag. Sci., 56, 83-93, 2000.

Commission of The European Communities (CEC): Proposal for a Directive of the European Parliament and of The Council establishing a framework for Community action to achieve a sustainable use of pesticides (presented by the Commission), Brussels, 12 July 2006, COM 373 final 2006/0132 (COD), 43, 2006.

Deng, H. L., Ye, M., Schaap, M. G., and Khaleel, R.: Quantification of uncertainty in pedotransfer function-based parameter estimation for unsaturated flow modeling, Water Resour. Res., 45, W04409, doi:10.1029/2008wr007477, 2009.

Djodjic, F., Börling, K., and Bergström, L.: Phosphorus leaching in relation to soil type and soil phosphorus content, J. Environ. Qual., 33, 678-684, 2004.

Dubus, I. G., Brown, C. D., and Beulke, S.: Sources of uncertainty in pesticide fate modelling, Sci. Total Environ., 317, 53-72, 
2003.

Finke, P. A., Wösten, J. H. M., and Jansen, M. J. W.: Effects of uncertainty in major input variables on simulated functional soil behaviour, Hydrol. Process., 10, 661-669, 1996.

Flury, M. and Papritz, A.: Bromide in the Natural Environment: Occurrence and Toxicity, J. Environ. Qual., 22, 747-758, doi:10.2134/jeq1993.00472425002200040017x, 1993.

FOCUS: FOCUS Surface water scenarios in the EU evaluation process under 91/414/EEC, EC document reference SANCO/4802/2001-rev 2, 245, 2001.

Gerke, H. H.: Preferential flow descriptions for structured soils, J. Plant Nutr. Soil Sci., 169, 382-400, doi:10.1002/jpln.200521955, 2006.

Gerke, H. H. and van Genuchten, M. T.: Macroscopic representation of structural geometry for simulating water and solute movement in dual-porosity media, Adv. Water Resour., 19, 343-357, doi:10.1016/0309-1708(96)00012-7, 1996.

Heuvelink, G. B. M., Burgers, S., Tiktak, A., and Van Den Berg, F.: Uncertainty and stochastic sensitivity analysis of the GeoPEARL pesticide leaching model, Geoderma, 155, 186-192, doi:10.1016/j.geoderma.2009.07.004, 2010.

Jarvis, N., Lindahl, A., Messing, I., Stenemo, F., Hollis, J., Reichenberger, S., and Dubus, I. G.: Algorithm to completely parameterise MACRO from basic soil property data, DL21 of the FP6 EU-funded FOOTPRINT project, 18, 2007.

Jarvis, N.: Near-Saturated Hydraulic Properties of Macroporous Soils, Vadose Zone J., 7, 1256-1264, doi:10.2136/vzj2008.0065, 2008.

Jarvis, N. J.: Modelling water and solute transport in macroporous soil. II. Chloride breakthrough under non-steady flow, J. Soil Ssci., 42, 71, doi:10.1111/j.1365-2389.1991.tb00092.x, 1991.

Jarvis, N. J.: A review of non-equilibrium water flow and solute transport in soil macropores: principles, controlling factors and consequences for water quality, Eur. J. Soil Sci., 58, 523-546, doi:10.1111/j.1365-2389.2007.00915.x, 2007.

Jarvis, N. J., Zavattaro, L., Rajkai, K., Reynolds, W. D., Olsen, P. A., McGechan, M., Mecke, M., Mohanty, B., Leeds-Harrison, P. B., and Jacques, D.: Indirect estimation of near-saturated hydraulic conductivity from readily available soil information, Geoderma, 108, 1-17, 2002.

Jarvis, N. J., Moeys, J., Hollis, J. M., Reichenberger, S., Lindahl, A. M. L., and Dubus, I. G.: A Conceptual Model of Soil Susceptibility to Macropore Flow, Vadose Zone J., 8, 902-910, doi:10.2136/vzj2008.0137, 2009.

Kirchmann, H.: Properties and classification of soils of the Swedish long-term fertility experiments .1. Sites at Fors and Kungsangen, Acta Agr. Scand., 41, 227-242, doi:10.1080/00015129109439905, 1991.

Kirchmann, H., Eriksson, J., and Snall, S.: Properties and classification of soils of the Swedish long-term fertility experiments - IV. Sites at Ekebo and Fjardingslov, Acta Agric. Scand. Sect. B-Soil Plant Sci., 49, 25-38, doi:10.1080/09064719950135678, 1999.

Kirchmann, H., Snall, S., Eriksson, J., and Mattsson, L.: Properties and classification of soils of the Swedish long-term fertility experiments: V. Sites at Vreta Kloster and Hogasa, Acta Agric. Scand. Sect. B-Soil Plant Sci., 55, 98-110, doi:10.1080/09064710510008711, 2005.

Köhne, J. M., Köhne, S., and Simunek, J.: A review of model applications for structured soils: a) Water flow and tracer transport, J. Contam. Hydrol., 104, 4-35, doi:10.1016/j.jconhyd.2008.10.002, 2009a.

Köhne, J. M., Köhne, S., and Simunek, J.: A review of model applications for structured soils: b) Pesticide transport, J. Contam. Hydrol., 104, 36-60, doi:10.1016/j.jconhyd.2008.10.003, 2009b.

Larsbo, M. and Jarvis, N. J.: MACRO 5.0. A model of water flow and solute transport in macroporous soils, Technical description, Swedish University of Agricultural Sciences, Uppsala, 52, 2003.

Larsbo, M., Roulier, S., Stenemo, F., Kasteel, R., and Jarvis, N.: An improved dual-permeability model of water flow and solute transport in the vadose zone, Vadose Zone J., 4, 398-406, doi:10.2136/vzj2004.0137, 2005.

Leterme, B., Vanclooster, M., van der Linden, T., Tiktak, A., and Rounsevell, M. D. A.: Including Spatial Variability in Monte Carlo Simulations of Pesticide Leaching, Environ. Sci. Technol., 41, 7444-7450, doi:10.1021/es0714639, 2007.

Lin, L. I.: A concordance correlation-coefficient to evaluate reproducibility, Biometrics, 45, 255-268, 1989.

Lindahl, A. M. L., Dubus, I. G., and Jarvis, N. J.: Site Classification to Predict the Abundance of the Deep-Burrowing Earthworm Lumbricus terrestris L, Vadose Zone J., 8, 911-915, doi:10.2136/vzj2008.0140, 2009.

McGrath, G. S., Hinz, C., and Murugesu, S.: A preferential flow leaching index, Water Resour. Res., 45, W11405, doi:10.1029/2008WR007265, 2009.

Nash, J. E. and Sutcliffe, J. V.: River flow forecasting through conceptual models, Part I - A discussion of principles, J. Hydrol., 10, 282-290, 1970.

Nolan, B. T., Dubus, I. G., and Surdyk, N.: A refined lack-of-fit statistic to calibrate pesticide fate models for responsive systems, Pest Manag. Sci., 65, 1367-1377, 2009.

Persson, G.: Comparishon of simulated water balance for willow, spruce, grass ley and barley, Nord. Hydrol., 28, 85-98, 1997.

R. Development Core Team: A Language and Environment for Statistical Computing, R Foundation for Statistical Computing, ISBN 3-900051-07-0, Vienna, Austria, 2011.

Roulier, S., Baran, N., Mouvet, C., Stenemo, F., Morvan, X., Albrechtsen, H. J., Clausen, L., and Jarvis, N.: Controls on atrazine leaching through a soil-unsaturated fractured limestone sequence at Brevilles, France, J. Contam. Hydrol., 84, 81-105, doi:10.1016/j.jconhyd.2005.12.004, 2006.

Saxena, R. K., Jarvis, N. J., and Bergström, L.: Interpreting nonsteady state tracer breakthrough experiments in sand and clay soils using a dual-porosity model, J. Hydrol., 162, 279-298, 1994.

Schaap, M. G., Leij, F. J., and van Genuchten, M. T.: ROSETTA: a computer program for estimating soil hydraulic parameters with hierarchical pedotransfer functions, J. Hydrol., 251, 163-176, doi:10.1016/s0022-1694(01)00466-8, 2001.

Schaefli, B. and Gupta, H. V.: Do Nash values have value?, Hydrol. Process., 21, 2075-2080, doi:10.1002/hyp.6825, 2007.

Seibert, J.: On the need for benchmarks in hydrological modelling, Hydrol. Process., 15, 1063-1064, 2001.

Šimùnek, J., Jarvis, N. J., van Genuchten, M. T., and Gärdenäs, A.: Review and comparison of models for describing nonequilibrium and preferential flow and transport in the vadose zone, J. Hydrol., 272, 14-35, 2003.

Soutter, M. and Pannatier, Y.: Groundwater vulnerability to pesticide contamination on a regional scale, J. Environ. Qual., 25, 
439-444, 1996.

Stevenson, M., Nunes, T., Sanchez, J., and Thornton, R.: epiR: Functions for analysing epidemiological data, R package version 0.9-22., 2009.

Tiktak, A., de Nie, D., van der Linden, T., and Kruijne, R.: Modelling the leaching and drainage of pesticides in the Netherlands: the GeoPEARL model, Agronomie, 22, 373-387, doi:10.1051/agro:2002022, 2002.

van Genuchten, M. T.: A closed form equation for predicting the hydraulic conductivity of unsaturated soils, Soil Sci. Soc. Am. J., 44, 892-898, 1980.

Vanderborght, J. and Vereecken, H.: Review of dispersivities for transport modeling in soils, Vadose Zone J., 6, 29-52, doi:10.2136/vzj2006.0096, 2007.

Vanderborght, J., Tiktak, A., Boesten, J. J. T. I., and Vereecken, H.: Effect of pesticide fate parameters and their uncertainty on the selection of "worst-case" scenarios of pesticide leaching to groundwater, Pest Manag. Sci., 67, 294-306, 2011.
Vereecken, H., Weynants, M., Javaux, M., Pachepsky, Y., Schaap, M. G., and van Genuchten, M. T.: Using Pedotransfer Functions to Estimate the van Genuchten-Mualem Soil Hydraulic Properties: A Review, Vadose Zone J., 9, 795-820, doi:10.2136/vzj2010.0045, 2010.

Wagenet, R. J. and Hutson, J. L.: Scale-dependency of solute transport modeling/GIS applications, J. Environ. Qual., 25, 499-510, 1996.

Wösten, J. H. M., Lilly, A., Nemes, A., and Le Bas, C.: Development and use of a database of hydraulic properties of European soils, Geoderma, 90, 169-185, 1999.

Zehe, E., Elsenbeer, H., Lindenmaier, F., Schulz, K., and Blöschl, G.: Patterns of predictability in hydrological threshold systems, Water Resour. Res., 43, W07434, doi:10.1029/2006wr005589, 2007. 